\title{
Lipopolysaccharide-Induced Sickness Behavior in Lactating Rats Decreases Ultrasonic Vocalizations and Exacerbates Immune System Activity in Male Offspring
}

\author{
Amanda F. Nascimento $^{a} \quad$ Glaucie Jussilane Alves $^{a}$ Cristina O. Massoco ${ }^{a}$ \\ Elizabeth Teodorov ${ }^{c}$ Luciano F. Felicio ${ }^{a}$ Maria Martha Bernardi ${ }^{b, c}$ \\ ${ }^{\mathrm{a}}$ Department of Pathology, School of Veterinary Medicine, University of São Paulo, and ${ }^{\mathrm{b}}$ Graduate Program of \\ Environmental and Experimental Pathology, Graduate Program of Dentistry, Paulista University, UNIP, São Paulo, \\ and ${ }^{\mathrm{C}}$ Mathematics, Computing and Cognition Center, Federal University of ABC, Santo André, Brazil
}

\section{Key Words}

Lactation · Maternal care · Ultrasonic vocalization .

Inflammation · Immune system

\begin{abstract}
Objective: The present study analyzed the effects of lipopolysaccharide (LPS) on maternal behavior during lactation and possible correlations with changes in emotional and immune responses in offspring. Methods: Lactating rats received $100 \mu \mathrm{g} / \mathrm{kg}$ LPS, and the control group received saline solution on lactation day (LD) 3. Maternal general activity and maternal behavior were observed on LD5 (i.e. the day that the peak of fever occurred). In male pups, hematological parameters and ultrasonic vocalizations (USVs) were assessed on LD5. At weaning, an additional dose of LPS (50 $\mu \mathrm{g} /$ $\mathrm{kg}$, i.p.) was administered in male pups, and open-field behavior, oxidative burst and phagocytosis were evaluated. Results: A reduction in the time in which dams retrieved the pups was observed, whereas no effects on maternal aggressive behavior were found. On LD5, a reduction of the frequency of USVs was observed in pups, but no signs of inflammation were found. At weaning, an increase in immune system activity was observed, but no differences in open-field behavior were found. Conclusion: These results indicate that inflammation in lactating mothers disrupted mother/
\end{abstract}

(C) 2014 S. Karger AG, Basel

1021-7401/14/0224-0213\$39.50/0 pup interactions and may have produced short- and longterm effects on pup behavior as well as biological pathways that modulate inflammatory responses to bacterial endotoxin challenge in pups.

(c) 2014 S. Karger AG, Basel

\section{Introduction}

Sick animals display a range of organized behaviors, collectively known as sickness behavior $[1,2]$. Symptoms of the sickness response can be produced experimentally by injecting lipopolysaccharide (LPS), an endotoxin that mimics infection by Gram-negative bacteria and activates the immune system to release proinflammatory cytokines, such as interleukin (IL)-1 $\beta$, tumor necrosis factor (TNF)- $\alpha$ and IL-6 [3, 4]. LPS induces fever [5], suppresses gonadal hormone release $[6,7]$ and potently activates the hypothalamic-pituitary-adrenal (HPA) axis [8]. Several authors have reported that LPS also affects central nervous system activity, leading to sickness behavior in many species $[3,9,10]$. The innate immune system is responsible for many of the acute sickness symptoms related to systemic inflammation or infection $[11,12]$. LPSinduced sickness behavior is generally characterized by decreases in exploratory activity [2], social behavior [13],

Dr. Maria Martha Bernardi Paulista University, UNIP Campus Indianapolis, Rua Dr. Bacelar, 1212 São Paulo, SP 04026-002 (Brazil)

E-Mail marthabernardi@gmail.com 
ingestive behavior [14] and sexual behavior [15]. It also induces anhedonia and causes poor learning and cognitive function [16].

Infections during the perinatal and postnatal periods are frequent and can lead to serious morbidity and mortality among both mothers and their offspring [17-20]. However, little is known about the effects of infection in lactating women on mother-pup interactions.

In rats, acute LPS administration early in life induces symptoms that resemble those seen in adult animals, including decreased activity, HPA activation and fever [2125]. Late maternal inflammation disrupts mother/pup interactions, resulting in long-lasting effects on pup behavior and alterations in biological pathways, thereby programming prepubertal behavior and the pups' inflammatory responses after bacterial endotoxin treatment [26]. Single early prenatal LPS exposure also impairs striatal monoamines and maternal care in female rats [27].

Behavioral responses to endotoxin administration are somewhat plastic and can be altered by the immediate environmental or situational context $[28,29]$. Aubert et al. [30] reported that building behavior was inhibited by LPS when the animals were housed at mild ambient temperatures, but not at low temperature. Weil et al. [31] observed that maternal aggression was not suppressed by LPS-evoked immune activation at doses that attenuated other aspects of maternal and social behavior. Reproductive behaviors were also modulated by the situational context. Male rats suppressed the symptoms of sickness behavior to mate, whereas male mice showed an increase in the sickness response when exposed to a female in estrus [32].

The present study analyzed the possible effects of LPS on maternal care during lactation and the changes in the emotional and immune responses of offspring. To test whether adaptive maternal/pup interactions were affected by LPS-induced sickness behavior in mothers, maternal behavior and ultrasonic vocalizations (USVs) in pups were examined. Previously, LPS-induced ( $100 \mu \mathrm{g} / \mathrm{kg}$, i.p.) sickness behavior was compared among lactating and virgin rats. LPS-induced fever was attenuated in lactating female rats. Nevertheless, LPS exposure induced several signs of sickness behavior, including decreases in food consumption and body weight gain, and promoted adipsia in both virgin and lactating female rats. Because the peak of LPS-induced fever occurs $48 \mathrm{~h}$ after treatment, female maternal behavior was observed on postnatal day (PND) 5 in the present study [5]. The influence on the pups' immune response to a challenge dose of LPS was also examined at weaning.

\section{Material and Methods}

\section{Animals}

Lactating female Wistar rats from our own colony, weighing 220-260 g, and their pups (7 pups per dam, 4 male and 3 female) were used. These animals were individually housed in polypropylene cages $(38 \times 32 \times 16 \mathrm{~cm})$ under conditions of controlled room temperature $\left(22 \pm 2^{\circ} \mathrm{C}\right)$, humidity $(65-70 \%)$ and artificial lighting (12/12 $\mathrm{h} \mathrm{light/dark} \mathrm{cycle;} \mathrm{lights} \mathrm{on} \mathrm{at} 6.00$ a.m.) with free access to Nuvilab rodent chow (Nuvital, São Paulo, Brazil) and filtered water. Sterilized and residue-free wood shavings were used as bedding material. The animals were maintained in accordance with the guidelines of the Committee on Care and Use of Laboratory Animal Resources of the School of Veterinary Medicine, University of São Paulo, São Paulo, Brazil (protocol No. 1881/2010-FMVZ-USP). These guidelines are similar to those of the US National Research Council.

\section{Treatments}

LPS (from Escherichia coli; serotype 0127:B8, Sigma, St. Louis, Mo., USA) was dissolved in saline $(50 \mu \mathrm{g} / \mathrm{ml} \mathrm{LPS}$ in $0.9 \% \mathrm{NaCl}$ solution) and administered intraperitoneally in lactating female rats [i.e. on lactation day (LD) 3] at a dose of $100 \mu \mathrm{g} / \mathrm{kg}$. This dose was chosen because it has been shown to induce behavioral and endocrine alterations and increase cytokines at the placental level [33, 34]. The control group consisted of lactating female rats treated with saline. Each female rat was administered $0.2 \mathrm{ml} / 100 \mathrm{~g}$ saline (LPS solution).

\section{Procedures}

\section{Maternal Studies}

General Activity in the Open Field

This behavioral model was used to investigate the possible motor alterations caused by LPS-induced sickness behavior that could interfere with maternal behavior performance. Lactating female rats (10/group) were treated with either $100 \mu \mathrm{g} / \mathrm{kg}$ LPS (i.p.) or vehicle ( $\mathrm{NaCl} 0.9 \%$, i.p.) and observed on LD5. The open field consisted of a round wooden arena with an acrylic washable covering $(90 \mathrm{~cm}$ in diameter, $28-\mathrm{cm}$-high walls) that was painted white and subdivided into 25 parts [35]. For the observations, each dam was individually placed in the center of the apparatus, and the following parameters were measured for 3 min: locomotion (i.e. the number of floor units entered with both feet) and rearing frequencies (i.e. the number of times the rodents stood on their hind legs) and immobility time (seconds without movements). Hand-operated counters and stopwatches were used to manually count these behaviors. To minimize the influence of possible circadian changes on open-field behavior, the rodents were observed at the same time of day $(2.00-5.00$ p.m.) during each session. The device was washed with a $5 \%$ alcohol/water solution before the animals were placed in it to obviate the possible biasing effects caused by odor cues left by previous rats. 
Maternal Behavior

Maternal behavior was analyzed as previously described [15] and observed on LD5 ( $\mathrm{n}=10$ dams/group) between 8.00 and 11.00 a.m. The pups were removed from their dams, placed in another cage and kept warm. Immediately following separation, the presence of a nest in the home cage was evaluated. Sixty minutes after maternal separation, all of the pups were returned to their mothers' cages and maternal behavior was examined. The latency (in seconds) to retrieve the first, second, third and all pups, the total time (in minutes) used to carrying all pups, and the duration and number of animals that exhibited full maternal behavior were recorded. The dams were considered to display full maternal behavior if they transferred all of the pups to the nest and displayed nursing behavior with their back arched over the pups for 3 consecutive minutes.

Maternal Aggressive Behavior

On LD5 ( $\mathrm{n}=10$ /group), after the maternal behavior test, maternal aggressive behavior was assessed. These rats were subjected to a 10-min maternal defense test [36]. A male Wistar rat (i.e. intruder) was introduced into the home cage of the dam and offspring. Intruder rats were only used once. Behaviors against the intruder during the maternal defense test were recorded using a remote digital camcorder, and offensive behavior by the resident (dam) was later analyzed, including the latency to the first attack (in seconds), attack frequency and total duration of attacks (in seconds).

\section{Pup Studies on PND5}

Ultrasonic Vocalization

On PND5, 1 male pup from each experimental and control litter ( $n=10$ /group) was examined for USVs following maternal isolation. Rodent pups emit vocalizations (30- to $50-\mathrm{kHz}$ band frequency) when isolated from their mothers, and these vocalizations are thought to solicit maternal interactions $[37,38]$. The PND5 time point was chosen to investigate mother/pup interactions. Immediately after the pups were isolated from their nests and mothers, they were individually placed in a polypropylene cage $(30 \times 20 \times 12 \mathrm{~cm})$, with the floor covered with bedding material, and brought to the testing room that was separate from the housing room. The testing room was maintained at a controlled temperature of $22 \pm 2{ }^{\circ} \mathrm{C}$. USVs were detected using an ultrasonic microphone (Petterson model D940 ultrasound detector) that was tuned to a range centered at $40 \mathrm{kHz}$ and placed $10 \mathrm{~cm}$ away from the bedding. The vocalizations were recorded as a digital WAV file (HP Pavilion dv5 notebook). The latency to the first USV (in seconds) and total time of USVs over a period of $5 \mathrm{~min}$ were measured. An observer who was blind to the treatment groups and hypotheses of the present study analyzed the digital recordings.

\section{Hematological Analyses}

Other male pups from control and experimental dams were used in this experiment. The rats at PND5 were euthanized with $100 \% \mathrm{CO}_{2}$ on $\mathrm{LD} 5$, and blood was collected in ethylenediaminetetraacetic acid (EDTA)-coated microtubes from the trunk. Blood smears were stained with Giemsa for differential white blood cell counts. For the analysis of hematocrit, red blood cells, white blood cells and differential leukocyte counts (i.e. lymphocytes, neutrophils, eosinophils, monocytes and basophils), the samples were collected into tubes that contained EDTA K2 (BD Vacutainer K2E,
Becton Dickinson, Plymouth, UK) and stored at $5^{\circ} \mathrm{C}$ until analysis using an ADVIA 120 hematology system (Bayer Corporation Diagnostic Division, Tarrytown, N.Y., USA).

\section{Pup Studies on LD21}

General Activity in the Open Field

On PND21, 1 male pup from each dam $(n=7 /$ group) received $50 \mu \mathrm{g} / \mathrm{kg}$ LPS (i.p.) $2 \mathrm{~h}$ before general activity was evaluated in the open field. This apparatus was similar to the one employed for adult female rats, but it was adapted to the size of the pups [39, 40]. The open field consisted of a round wooden arena $(40 \mathrm{~cm}$ in diameter, $40-\mathrm{cm}$-high walls) that was painted black and divided into 25 parts. The apparatus was elevated $100 \mathrm{~cm}$ above the floor. For the observations, each pup was individually placed in the center of the apparatus, and the following parameters were recorded: locomotor frequency (i.e. number of floor units entered), rearing frequency (i.e. number of times the animal stood on its hind legs) and immobility time (i.e. total time in seconds of lack of movement) during $5 \mathrm{~min}$. The apparatus was washed with a $5 \%$ alcohol/water solution before the animals were placed into it to negate the possible biasing effects caused by odor cues left by previous rats.

\section{Sampling of Peripheral Blood Neutrophils and Flow}

Cytometry

Blood was withdrawn directly from the left ventricle into lithium heparin Vacuntainer tubes (Becton Dickinson) immediately after each animal was euthanized in $\mathrm{CO}_{2}$. Blood samples $(100 \mu \mathrm{l})$ were used to assess the phagocytic activity and the oxidative burst of neutrophils as described below.

A flow cytometer (FACSCalibur ${ }^{\circledR}$, Becton Dickinson Immunocytometry Systems, San Jose, Calif., USA) interfaced with a Macintosh G4 computer was used. Data from 10,000 events was collected in list mode and analyzed in Cell Quest software (Becton Dickinson Immunocytometry Systems). Cell populations were identified based on their properties on forward-scatter versus sidescatter plots, mechanically sorted, and evaluated through light microscopy after staining with Giemsa. Fluorescence data were collected on a log scale. Green fluorescence from DCFH-DA (2', 7' dichlorofluorescein diacetate, Molecular Probes, Eugene, Oreg., USA) was measured at $530 \pm 30 \mathrm{~nm}$ (FL1 detector); red fluorescence from propidium iodide (PI)-labeled Staphylococcus aureus (Sigma) was measured at $585 \pm 42 \mathrm{~nm}$ (FL2). PI and DCFH-DA fluorescence were analyzed after compensation to correct for possible crossing over between PI and DCFH-DA signals. The data from 10,000 events were collected, and data from leukocytes were collected applying gates that sorted out lymphocyte and cellular debris clusters.

Oxidative Burst and Phagocytosis. The substances used for triggering the oxidative burst were phorbol myristate acetate (PMA; $100 \mathrm{ng})$ and $S$. aureus $\left(2.4 \times 10^{9}\right.$ bacteria/ml). Briefly, $100 \mu \mathrm{l}$ of whole blood $\left(2 \times 10^{5}\right.$ cells $\left./ 100 \mu \mathrm{l}\right)$ was mixed with $200 \mu \mathrm{l}$ of DCFHDA $(0.3 \mathrm{mM})$ in PBS and $100 \mu \mathrm{l}$ of either PI-labeled S. aureus or PMA in separate polypropylene tubes. Samples were incubated under agitation at $37^{\circ} \mathrm{C}$ for $20 \mathrm{~min}$. Reactions were stopped by adding $2 \mathrm{ml}$ of cold EDTA solution ( $3 \mathrm{mM}$ ) in order to terminate phagocytosis. After centrifugation ( $250 \mathrm{~g}$ for $10 \mathrm{~min}$ ), erythrocytes were lysed from all samples with sterile $0.2 \% \mathrm{NaCl}(2 \mathrm{ml} /$ tube $)$ for $20 \mathrm{~s}$. Immediately after that, $1.6 \% \mathrm{NaCl}$ sterile solution $(2 \mathrm{ml})$ was added to each sample to restore isotonicity. Samples were then 
Fig. 1. Experimental design.
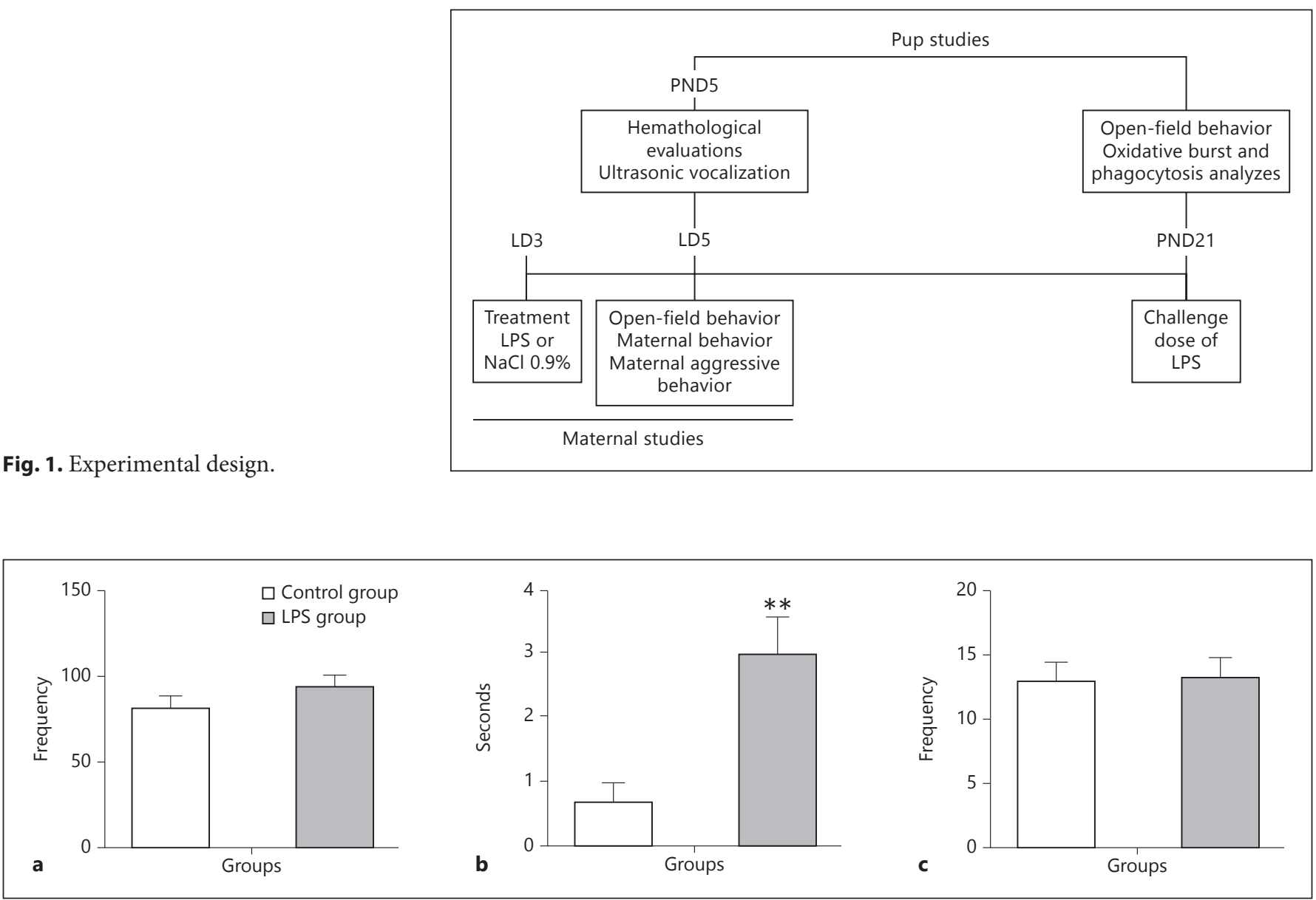

Fig. 2. Open-field behavior of dams treated with $100 \mu \mathrm{g} / \mathrm{kg}$ LPS on LD3 and observed on LD5: locomotion (a), immobility (b) and rearing $(\mathbf{c}) ; \mathrm{n}=10$ /group. ${ }^{*} \mathrm{p}<0.003$ in relation to control group; Student's t test. Values are mean \pm SEM.

centrifuged ( $250 \mathrm{~g}$ for $10 \mathrm{~min}$ ) and the cell pellets resuspended in $1 \mathrm{ml}$ of cold EDTA ( $3 \mathrm{~mm}$ ) for flow cytometry. Direct measurements of mean fluorescence of green and red channels were recorded as oxidative burst and phagocytosis, respectively. Quantification of phagocytosis and oxidative burst was estimated as proposed elsewhere [41], i.e. using mean PI and DCFH-DA fluorescence/cell, respectively. The percentage of phagocytosis (percentage of neutrophils with ingested bacteria) was expressed by the number of neutrophils with red fluorescence, divided by the total number of cells (multiplied by 100). The same pups observed in the open field were used in this experiment.

\section{Experimental Design}

The lactating rats were randomly distributed into control and experimental groups ( $n=10$ /group). The experimental group received $100 \mu \mathrm{g} / \mathrm{kg}$ LPS, and the control group received saline solution on LD3. Maternal general activity and the maternal behavior were observed on LD5 when the peak of fever occurred [5]. In male pups ( $\mathrm{n}=7$ /group), the hematological parameters and vo- calization were assessed on PND5. At weaning, an additional dose of LPS $(50 \mu \mathrm{g} / \mathrm{kg}$, i.p.) was administered to male pups in both groups, and open-field behavior, oxidative bursts and phagocytosis were observed. Figure 1 shows the experimental design.

\section{Results}

\section{Maternal Studies}

\section{General Activity in the Open Field}

Figure 2 illustrates the general activity of dams treated or not with LPS in the LD5. No differences were observed between groups in locomotion $(\mathrm{t}=1.52$, d.f. $=18, \mathrm{p}=$ $0.15)$ and rearing $(t=0.04$, d.f. $=18, p=0.97)$. An increased immobility duration was observed in dams exposed to LPS relative to controls $(\mathrm{t}=3.45$, d.f. $=18, \mathrm{p}=$ $0.003)$. 
Table 1. Maternal behavior of lactating rats treated with $100 \mu \mathrm{g} / \mathrm{kg}$ LPS or saline solution (0.9\%, i.p.) on PND3 and observed on LD5

\begin{tabular}{lccc}
\hline Parameter & Groups & p \\
\cline { 2 - 3 } & control & experimental & \\
\hline Maternal behavior & & & 0.08 \\
$\quad$ Latency to retrieve of 1st pup, s & $4.30 \pm 0.65$ & $2.80 \pm 0.51$ & 0.24 \\
Latency to retrieve of 2nd pup, s & $12.60 \pm 2.22$ & $11.50 \pm 0.58$ & 0.001 \\
Latency to retrieve of 3rd pup, s & $191.80 \pm 56.10$ & $395.26 \pm 27.27$ & 0.08 \\
Latency to retrieve of all pups, s & $1,999.14 \pm 546.46$ & $859.98 \pm 345.14$ & 0.78 \\
Total time carrying pups, min & $6.6 \pm 1.15$ & $4.90 \pm 4.88$ & 0.47 \\
Females presenting full maternal behavior, \% & 80 & 100 & 0.21 \\
Number of pups at the end of experiment, \% & 80 & 100 & 0.78 \\
Maternal aggressive behavior & & & $14.60 \pm 3.12$ \\
Latency to first attack, s & $16.50 \pm 5.99$ & $6.60 \pm 1.15$ & 0.45 \\
Attack frequency & $4.90 \pm 1.88$ & $16.50 \pm 6.00$ & 0.77 \\
Total duration of attacks, s & $14.60 \pm 3.17$ & & \\
\hline
\end{tabular}

Data are presented as means \pm SEM or percentage. $n=10$ /group. Student's t test.

\section{Maternal Behavior}

Table 1 shows maternal behavior in female rats treated with $100 \mu \mathrm{g} / \mathrm{kg}$ LPS or saline on LD3 and observed on LD5. The LPS-treated animals exhibited shorter latencies to retrieve the third pup compared with controls $(\mathrm{t}=$ 1.816 , d.f. $=18, \mathrm{p}<0.001)$. No significant differences were found in the other parameters between groups.

\section{Maternal Aggressive Behavior}

Table 1 shows maternal aggressive behavior in the same rats that were observed for maternal behavior. No significant differences were found between groups in any of the behavioral parameters of maternal aggression.

\section{Pup Studies on LD5}

\section{Ultrasonic Vocalizations}

Figure 3 shows the pup USV data. The number of USV events was reduced in experimental pups compared with the control group $(\mathrm{t}=3.45$, d.f. $=12, \mathrm{p}=0.005)$. However, the total duration of USVs was not different between groups $(\mathrm{t}=1.29$, d.f. $=12, \mathrm{p}=0.23)$.

\section{Hematological Studies}

The evaluation of blood samples from pups on LD5 revealed no differences for the pups from dams that were treated with $100 \mu \mathrm{g} / \mathrm{kg}$ LPS compared with the saline group (data not shown).

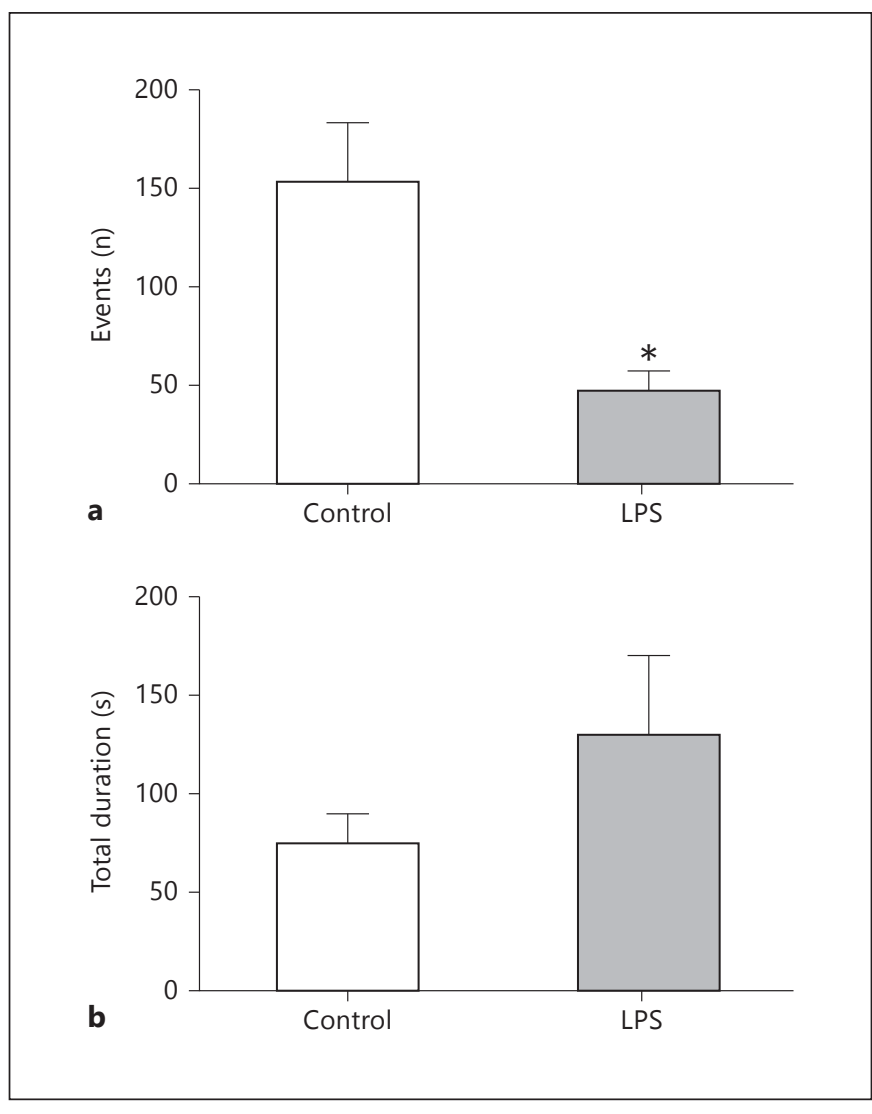

Fig. 3. USVs on LD5 in rat pups from mothers that were exposed to LPS on LD3. The number of events (a) and the total duration in seconds (b) are presented; $\mathrm{n}=7$ /group. ${ }^{*} \mathrm{p}<0.05$ in relation to control group; Student's t test.

Neuroimmunomodulation 2015;22:213-221 
Table 2. Leukocyte oxidative burst by $S$. aureus and percentage of phagocytosis of rat pups from mothers treated with $100 \mathrm{mg} / \mathrm{kg} \mathrm{LPS}$ or saline solution on PND3 and challenged with the same endotoxin $(50 \mathrm{mg} / \mathrm{kg}) 2 \mathrm{~h}$ before the test

\begin{tabular}{lccc}
\hline & \multicolumn{2}{l}{ Groups } & \multirow{2}{*}{$\mathrm{p}$} \\
\cline { 2 - 3 } & control & experimental & \\
\hline $\begin{array}{l}\text { Phagocytosis, \% } \\
\begin{array}{c}\text { DCFH-DA, } \\
\text { mean fluorescence }\end{array}\end{array}$ & $25.08 \pm 2.95$ & $35.77 \pm 4.56$ & 0.0006 \\
$\begin{array}{c}\text { DCFH-DA + bacteria, } \\
\text { mean fluorescence }\end{array}$ & $211.08 \pm 25.79$ & $400.80 \pm 37.53$ & 0.001 \\
$\begin{array}{c}\text { Phagocytosis intensity, } \\
\text { mean fluorescence }\end{array}$ & $56.59 \pm 11.75$ & $58.04 \pm 10.63$ & 0.464 \\
$\begin{array}{c}\text { PMA, mean fluorescence } \\
\text { PMA }\end{array}$ & $1.15 \pm 0.04$ & $1.41 \pm 0.07$ & 0.007 \\
\hline
\end{tabular}

Data are presented as means \pm SEM (arbitrary units) or percentage. $n=7$ /group. Student's t test.

\section{Pup Studies on LD21}

\section{General Activity in the Open Field}

Student's $t$ test did not reveal differences in locomotion frequency $(\mathrm{t}=1.46$, d.f. $=12, \mathrm{p}=0.169)$ or rearing frequency $(\mathrm{t}=0.208$, d.f. $=12, \mathrm{p}=0.834)$ in male pups from dams that were treated with $100 \mu \mathrm{g} / \mathrm{kg}$ LPS on LD3 and challenged with $50 \mu \mathrm{g} / \mathrm{kg}$ LPS at weaning. No differences in the duration of immobility were observed between these groups $(t=0.748$, d.f. $=12, p=0.468$; see online suppl. fig. 1; for all online suppl. material, see www. karger.com/doi/10.1159/000363350).

\section{Oxidative Burst and Phagocytosis}

Rats from dams that were treated with $100 \mu \mathrm{g} / \mathrm{kg}$ LPS exhibited increases in stimulated leukocyte oxidative bursts by $S$. aureus $(\mathrm{t}=4.15$, d.f. $=12, \mathrm{p}<0.001)$, PMA $(\mathrm{t}=3.225$, d.f. $=12, \mathrm{p}=0.007)$ and the percentage of phagocytosis $(\mathrm{t}=4.57$, d.f. $=12, \mathrm{p}<0.0006)$ compared with the saline solution group (table 2).

\section{Discussion}

The present study analyzed the effects of LPS on maternal care during lactation and the possible correlation with changes in emotional and immune responses in pup offspring. The improvement in maternal care observed in LPS-treated dams may be a consequence of motivational changes in maternal care, in which pup retrieval and oth- er maternal care behaviors are motivated behaviors [4244]. The remarkable ability of postpartum females to successfully care for their developing offspring is subserved by a distributed neural network. The motivational circuitry efficiently and dynamically processes complex and constantly changing incoming environmental and puprelated stimuli, ultimately allowing the appropriate expression of maternal responsiveness throughout the postpartum period [45]. This improvement might not be a consequence of an increase in motor activity because the open-field data showed no significant differences in locomotion frequency between the control and LPS groups. In addition, an increased immobility was observed. Importantly, motor interference should be discarded because pup retrieval behavior and other maternal care behaviors involve a chain of motor responses elicited by various stimuli that emanate from the dams or pups, thus promoting orientation, attention and arousal [42].

Among the signs of LPS-induced sickness behavior, fever has been reported [1]. Fever, an adaptive reaction to pathogens $[1,46]$, results from a complex reaction in hypothalamic centers that inform the organism that the environmental temperature is low and induce an increase in body temperature [47]. At birth, rodent neonates have not yet developed thermoregulatory mechanisms, and maternal care is critical to maintain pup survival. Both pup retrieval and nest building are important for the thermoregulation of pups [30]. Retrieving behavior is directly linked to the survival of the litter and plays a major role in increasing the dam's inclusive fitness, defined by the number of offspring that survive and reproduce. Thus, maternal fever during lactation may signal to the mother that the environmental temperature is too low, and this sensory information may specifically increase the motivation of the dam to retrieve her pups. Therefore, the decrease in the latency to retrieve the first pup observed in lactating LPS-treated rats in the present study may be attributable to a slight improvement in maternal care. Alternatively, because maternal care has a thermoregulatory component, the motivation to retrieve the pups might have been mainly related to thermoregulation.

Maternal aggressive behavior was measured as the reaction of the mother to an unknown intruder introduced to the cage. No differences were observed in any of the maternal aggression parameters. Thus, despite having fever, the dams defended their pups against the intruder.

Maternal exposure to LPS on LD3 reduced the number of USVs in the pups on LD5, but not the duration of the 
USV events. This impairment exhibited by the pups was probably caused by the actions of maternal immunological mediators that were released from milk cells after LPS exposure. In this respect, $\mathrm{Na}$ and Seelig [48] reported TNF, IL- 6 and IL-2 production by rat milk cells in vitro following Trichinella spiralis infection. Nguyen et al. [49] detected the transfer of several cytokines by colostrum/ milk. They reported a correlation between the concentrations in sow serum and confirmed the transfer and persistence of maternal cytokines from colostrum/milk to neonates. Previously, Kirsten et al. [50] and Baharnoori et al. [51] reported an impairment of USVs in pups that were prenatally exposed to LPS. In the present study, LPS administered to dams during lactation also reduced USVs in their pups.

Altricial rodent pups emit USVs, which are whistlelike sounds with frequencies between 30 and $90 \mathrm{kHz}$. These signals play an important communicative role in mother-offspring interactions because they elicit a prompt caregiving response in the dam. Thus, in our experiment, the increase in maternal motivation did not result from pup's vocalizations, since they were reduced. We attributed these counterintuitive results to the relevance of thermoregulatory information received by the mothers relative to the pups UVS stimulus toward the mother. As previously stated, maternal fever during lactation may signal to the mother that the environmental temperature is too low, which implicates the survival of offspring. This information probably supplants the reduced pup USV stimulus toward the mother.

Because maternal sickness behavior during lactation is also accompanied by maternal stress [52, 53], exposure to LPS on LD3 may have affected the HPA axis in the offspring, which may be responsible for the changes observed herein [54]. A previous study reported a reduction of USVs in rat pups from dams exposed to LPS [50].

The lack of immune effects on LD5 observed in the present study could be explained by the high levels of corticosterone in milk. Brummelte et al. [55] reported that pups exposed to high gestational maternal corticosterone had higher corticosterone levels in stomach milk or the brain on LD7. Indeed, Yorty and Bonneau [56] demonstrated that acute stress increased corticosterone levels in serum and breast milk. The consumption of corticosterone in breast milk in newborn infants would result in the activation of the infants' own corticosterone. These authors concluded that corticosterone release via milk prevented the ability of the progeny to generate an adaptive immune response mediated by cells, illustrating the po-

LPS and Maternal-Pup Interaction tential importance of maternal stress in the resistance to infectious pathogens in neonates.

To test the sensitivity of pups to LPS-induced sickness behavior, we administered an additional dose of LPS in male pups at weaning, and evaluated exploratory behavior in the open field and some innate immune system parameters. No differences were found in any of the openfield parameters between the saline + LPS and LPS + LPS groups. This might be attributable to lower sensitivity to LPS-induced sickness behavior in prepubertal rats. To verify this hypothesis, we evaluated immune system activity at weaning. Surprisingly, pups from dams exposed to LPS exhibited an increase in immune system activation at weaning compared with controls. Additionally, we previously found that maternal exposure to LPS reduced the concentration of specific chemical elements, such as $\mathrm{Zn}$, $\mathrm{Cu}, \mathrm{Mg}$ and Se [unpubl. data], and this could be involved in the results observed in the oxidative burst and phagocytosis. These findings are in agreement with Bussière et al. [57] who observed in experimental Mg-deficient rats an increase in activity of phagocytosis and an oxidative burst of neutrophils. Interestingly, we previously observed that prenatal exposure to LPS during late pregnancy decreased TNF- $\alpha$ levels of pups challenged with the same endotoxin [26].

Several studies have shown that early activation of the immune system in response to either LPS or bacterial infection changed the innate immune response [58-61] and the sensorial and behavioral responses to LPS $[61,62]$. These effects were attributed to the release of glucocorticoids, promoted by early activation of the HPA axis [63]. However, the effects of early immune activation on later periods of life were discussed, rather than on the initial period of life as investigated in the present study. According to Levine [64], the levels of glucocorticoids during late pregnancy and the first days of life are still high in rat offspring. A period of hyporesponsiveness of the HPA axis is then observed, which lasts until PND14. Moreover, the levels of corticotropin-releasing factor and adrenocorticotropic hormone during the last 2 weeks of lactation are quite low [65]. Therefore, one may suggest that the increased response to an LPS challenge on LD1 is related to the lower glucocorticoid levels in pups.

\section{Conclusion}

LPS administration in rats during early lactation may facilitate the dam's retrieval of the first pup. We attribute this effect to maternal fever. The decrease in 
USVs in pups would ultimately result from maternal exposure to LPS by releasing cytokines in milk. Furthermore, maternal exposure to the endotoxin led to sensitization of the immune system in their offspring when challenged with LPS. Thus, the present results indicate that inflammation in lactating females disrupts mother/pup interactions, resulting in both short- and long-term effects on pup behavior and alterations in biological pathways. Therefore, bacterial endotoxin challenge in mothers might program the pups' inflammatory responses.

\section{Acknowledgments}

The authors are grateful to FAPESP for financial support (grant No. 2013/03912-0 and thematic grant 2009/51886-3). This study is part of the Master thesis of Amanda F. Nascimento, presented to the Programa de Pós-Graduação em Patologia Experimental e Comparada, Faculdade de Medicina Veterinária e Zootecnia da Universidade de São Paulo.

\section{Disclosure Statement}

The authors have no conflicts of interest to declare.

\section{References}

1 Hart BL: Biological basis of the behavior of sick animals. Neurosci Biobehav Rev 1988;12: 123-137.

2 Kinoshita D, Cohn DW, Costa-Pinto FA, de Sa-Rocha LC: Behavioral effects of LPS in adult, middle-aged and aged mice. Physiol Behav 2009;96:328-332.

-3 Aderem A, Ulevitch RJ: Toll-like receptors in the induction of the innate immune response. Nature 2000;406:782-787.

-4 Muller JM, Ziegler-Heitbrock HW, Baeuerle PA: Nuclear factor kappa B, a mediator of lipopolysaccharide effects. Immunobiology 1993; 187:233-256.

5 Nascimento A, Bernardi M, Pecorari V, Massoco C, Felicio L: Temporal analysis of lipopolysaccharide-induced sickness behavior in virgin and lactating female rats. Neuroimmunomodulation 2013;20:305-312.

-6 Agrawal V, Jaiswal MK, Jaiswal YK: Gonadal and nongonadal FSHR and LHR dysfunction during lipopolysaccharide induced failure of blastocyst implantation in mouse. J Assist Reprod Genet 2012;29:163-173.

7 Sheldahl LC, Marriott LK, Bryant DM, Shapiro RA, Dorsa DM: Neuroprotective effects of estrogen and selective estrogen receptor modulators begin at the plasma membrane. Minerva Endocrinol 2007;32:87-94.

8 Turnbull AV, Lee S, Rivier C: Mechanisms of hypothalamic-pituitary-adrenal axis stimulation by immune signals in the adult rat. Ann NY Acad Sci 1998;840:434-443.

-9 Avitsur R, Pollak Y, Yirmiya R: Different receptor mechanisms mediate the effects of endotoxin and interleukin- 1 on female sexual behavior. Brain Res 1997;773:149-161.

10 Saluk-Juszczak J, Wachowicz B: The proinflammatory activity of lipopolysaccharide (in Polish). Postepy Biochem 2005;51:280-287.

$\checkmark 11$ Medzhitov R, Janeway C Jr: Innate immunity. N Engl J Med 2000;343:338-344.

12 Rivest S: Molecular insights on the cerebral innate immune system. Brain Behav Immun 2003; 17:13-19.

13 Kirsten TB, Taricano M, Maiorka PC, Palermo-Neto J, Bernardi MM: Prenatal lipopoly- saccharide reduces social behavior in male offspring. Neuroimmunomodulation 2010; 17:240-251.

14 Exton MS: Infection-induced anorexia: active host defence strategy. Appetite 1997;29:369383.

15 Bernardi MM, Kirsten TB, Matsuoka SM, Teodorov E, Habr SF, Penteado SH, PalermoNeto J: Prenatal lipopolysaccharide exposure affects maternal behavior and male offspring sexual behavior in adulthood. Neuroimmunomodulation 2010;17:47-55.

16 Yirmiya R, Goshen I: Immune modulation of learning, memory, neural plasticity and neurogenesis. Brain Behav Immun 2011;25:181213.

17 Karolinski A, Mazzoni A, Belizan JM, Althabe F, Bergel E, Buekens P: Lost opportunities for effective management of obstetric conditions to reduce maternal mortality and severe maternal morbidity in Argentina and Uruguay. Int J Gynaecol Obstet 2010;110:175-180.

18 Hussein J, Mavalankar DV, Sharma S, D'Ambruoso L: A review of health system infection control measures in developing countries: what can be learned to reduce maternal mortality. Global Health 2011;7:14.

19 Bako B, Audu BM, Lawan ZM, Umar JB: Risk factors and microbial isolates of puerperal sepsis at the University of Maiduguri Teaching Hospital, Maiduguri, North-Eastern Nigeria. Arch Gynecol Obstet 2012;285:913917.

20 Callaghan WM, Creanga AA, Kuklina EV: Severe maternal morbidity among delivery and postpartum hospitalizations in the United States. Obstet Gynecol 2012;120: 1029-1036.

21 Shanks N, Meaney MJ: Hypothalamic-pituitary-adrenal activation following endotoxin administration in the developing rat: a $\mathrm{CRH}$ mediated effect. J Neuroendocrinol 1994;6: 375-383.

22 Walker FR, March J, Hodgson DM: Endotoxin exposure in early life alters the development of anxiety-like behaviour in the fischer 344 rat. Behav Brain Res 2004;154:63-69.
23 Xu M, Sulkowski ZL, Parekh P, Khan A, Chen T, Midha S, Iwasaki T, Shimokawa N, Koibuchi N, Zavacki AM, Sajdel-Sulkowska EM: Effects of perinatal lipopolysaccharide (LPS) exposure on the developing rat brain; modeling the effect of maternal infection on the developing human CNS. Cerebellum 2013;12:572586.

24 Auvin S, Porta N, Nehlig A, Lecointe C, Vallee L, Bordet R: Inflammation in rat pups subjected to short hyperthermic seizures enhances brain long-term excitability. Epilepsy Res 2009;86:124-130.

25 Avitsur R, Sheridan JF: Neonatal stress modulates sickness behavior. Brain Behav Immun 2009;23:977-985.

26 Penteado S, Massoco-Salles Gomes CO, Kirsten TB, Reis-Silva TM, Melo RC, Acenjo M, Queiroz-Hazarbassanov N, Bernardi MM: Prenatal lipopolysaccharide increases maternal behavior, decreases maternal odor preference, and induces lipopolysaccharide hyporesponsiveness. Psychol Neurosci 2013; 6:31-38.

27 Soto AM, Kirsten TB, Reis-Silva TM, Martins MF, Teodorov E, Florio JC, Palermo-Neto J, Bernardi MM, Bondan EF: Single early prenatal lipopolysaccharide exposure impairs striatal monoamines and maternal care in female rats. Life Sci 2013;92:852-858.

28 Avitsur R, Yirmiya R: Cytokines inhibit sexual behavior in female rats: I. Synergistic effects of tumor necrosis factor $a$ and interleukin-1. Brain Behav Immun 1999;13:14-32.

29 Bilbo SD, Drazen DL, Quan N, He L, Nelson RJ: Short day lengths attenuate the symptoms of infection in Siberian hamsters. Proc Biol Sci 2002;269:447-454.

30 Aubert A, Goodall G, Dantzer R, Gheusi G: Differential effects of lipopolysaccharide on pup retrieving and nest building in lactating mice. Brain Behav Immun 1997;11:107-118.

-31 Weil ZM, Bowers SL, Dow ER, Nelson RJ: Maternal aggression persists following lipopolysaccharide-induced activation of the immune system. Physiol Behav 2006;87:694699. 
-32 Weil ZM, Bowers SL, Pyter LM, Nelson RJ: Social interactions alter proinflammatory $\mathrm{cy}$ tokine gene expression and behavior following endotoxin administration. Brain Behav Immun 2006;20:72-79.

- 33 Kirsten TB, Taricano M, Maiorka PC, Palermo-Neto J, Bernardi MM: Prenatal lipopolysaccharide reduces social behavior in male offspring. Neuroimmunomodulation 2010; 17:240-251.

- 34 Bernardi MM, Kirsten TB, Matsuoka SM, Teodorov E, Habr SF, Penteado SH, PalermoNeto J: Prenatal lipopolysaccharide exposure affects maternal behavior and male offspring sexual behavior in adulthood. Neuroimmunomodulation 2009;17:47-55.

- 35 Broadhurst PL: Determinants of emotionality in the rat. I. Situational factors. Br J Psychol 1957;48:1-12.

- 36 Svare B, Betteridge C, Katz D, Samuels O: Some situational and experiential determinants of maternal aggression in mice. Physiol Behav 1981;26:253-258.

- 37 Insel TR, Hill JL, Mayor RB: Rat pup ultrasonic isolation calls: possible mediation by the benzodiazepine receptor complex. Pharmacol Biochem Behav 1986;24:1263-1267.

- 38 Ise S, Nagano N, Okuda S, Ohta H: Corticotropin-releasing factor modulates maternal separation-induced ultrasonic vocalization in rat pups via activation of CRF1 receptor. Brain Res 2008;1234:59-65.

-39 Faggin BM, Palermo-Neto J: Differential alterations in brain sensitivity to amphetamine and pentylenetetrazol in socially deprived mice. Gen Pharmacol 1985;16:299-302.

-40 Felicio LF, Palermo-Neto J, Nasello AG: Perinatal bromopride treatment: effects on motor activity and stereotyped behavior of offspring. Physiol Behav 1989;45:1081-1085.

-41 Hasui M, Hirabayashi Y, Kobayashi Y: Simultaneous measurement by flow cytometry of phagocytosis and hydrogen peroxide production of neutrophils in whole blood. J Immunol Methods 1989;117:53-58.

42 Stern JM: Multisensory regulation of maternal behavior and masculine sexual behavior: a revised view. Neurosci Biobehav Rev 1990; 14:183-200.

43 Stern JM, Protomastro M: Effects of low dosages of apomorphine on maternal responsiveness in lactating rats. Pharmacol Biochem Behav 2000;66:353-359.

44 Pedersen CA, Vadlamudi SV, Boccia ML, Amico JA: Maternal behavior deficits in nulliparous oxytocin knockout mice. Genes Brain Behav 2006;5:274-281.
45 Pereira M, Morrell JI: Functional mapping of the neural circuitry of rat maternal motivation: effects of site-specific transient neural inactivation. J Neuroendocrinol 2011;23: 1020-1035.

46 Damm J, Wiegand F, Harden LM, Gerstberger R, Rummel C, Roth J: Fever, sickness behavior, and expression of inflammatory genes in the hypothalamus after systemic and localized subcutaneous stimulation of rats with the toll-like receptor 7 agonist imiquimod. Neuroscience 2011;201:166-183.

47 Nakamura K: Central circuitries for body temperature regulation and fever. Am J Physiol Regul Integr Comp Physiol 2011; 301:R1207-R1228.

$48 \mathrm{Na}$ HR, Seelig LL Jr: In vitro TNF, IL-6 and IL-2 production by rat milk cells following Trichinella spiralis infection. J Reprod Immunol 1993;25:119-131.

49 Nguyen TV, Yuan L, Azevedo MS, Jeong KI, Gonzalez AM, Saif LJ: Transfer of maternal cytokines to suckling piglets: in vivo and in vitro models with implications for immunomodulation of neonatal immunity. Vet Immunol Immunopathol 2007;117:236-248.

-50 Kirsten TB, Chaves-Kirsten GP, Chaible LM, Silva AC, Martins DO, Britto LRG, Dagli MLZ, Torrao AS, Palermo-Neto J, Bernardi MM: Hypoactivity of the central dopaminergic system and autistic-like behavior induced by a single early prenatal exposure to lipopolysaccharide. J Neurosci Res 2012;90:19031912.

51 Baharnoori M, Bhardwaj SK, Srivastava LK: Neonatal behavioral changes in rats with gestational exposure to lipopolysaccharide: a prenatal infection model for developmental neuropsychiatric disorders. Schizophr Bull 2012;38:444-456.

52 Sominsky L, Meehan CL, Walker AK, Bobrovskaya L, McLaughlin EA, Hodgson DM: Neonatal immune challenge alters reproductive development in the female rat. Horm Behav 2012;62:345-355.

53 Kofman O: The role of prenatal stress in the etiology of developmental behavioural disorders. Neurosci Biobehav Rev 2002;26:457470.

54 Reul JM, Stec I, Wiegers GJ, Labeur MS, Linthorst AC, Arzt E, Holsboer F: Prenatal immune challenge alters the hypothalamicpituitary-adrenocortical axis in adult rats. J Clin Invest 1994;93:2600-2607.
5 Brummelte S, Schmidt KL, Taves MD, Soma KK, Galea LA: Elevated corticosterone levels in stomach milk, serum, and brain of male and female offspring after maternal corticosterone treatment in the rat. Dev Neurobiol 2010;70:714-725.

56 Yorty JL, Bonneau RH: Transplacental transfer and subsequent neonate utilization of herpes simplex virus-specific immunity are resilient to acute maternal stress. J Virol 2003;77: 6613-6619.

57 Bussière FI, Gueux E, Rock E, Girardeau JP Tridon A, Mazur A, Rayssiguier Y: Increased phagocytosis and production of reactive oxygen species by neutrophils during magnesium deficiency in rats and inhibition by high magnesium concentration. Br J Nutr 2002;87: 107-113

58 Bilbo SD, Levkoff LH, Mahoney JH, Watkins LR, Rudy JW, Maier SF: Neonatal infection induces memory impairments following an immune challenge in adulthood. Behav Neurosci 2005;119:293-301.

-59 Ellis S, Mouihate A, Pittman QJ: Early life immune challenge alters innate immune responses to lipopolysaccharide: implications for host defense as adults. FASEB J 2005;19: 1519-1521.

60 Spencer SJ, Heida JG, Pittman QJ: Early life immune challenge - effects on behavioural indices of adult rat fear and anxiety. Behav Brain Res 2005; 164:231-238.

61 Walker FR, Knott B, Hodgson DM: Neonatal endotoxin exposure modifies the acoustic startle response and circulating levels of corticosterone in the adult rat but only following acute stress. J Psychiatr Res 2008;42:10941103.

-62 Harre EM, Galic MA, Mouihate A, Noorbakhsh F, Pittman QJ: Neonatal inflammation produces selective behavioural deficits and alters $\mathrm{N}$-methyl-D-aspartate receptor subunit mRNA in the adult rat brain. Eur J Neurosci 2008;27:644-653.

63 Mouihate A, Harre EM, Martin S, Pittman QJ Suppression of the febrile response in late gestation: evidence, mechanisms and outcomes. J Neuroendocrinol 2008;20:508-514.

64 Levine S: Primary social relationships influence the development of the hypothalamicpituitary-adrenal axis in the rat. Physiol Behav 2001;73:255-260.

65 Walker CD, Sapolsky RM, Meaney MJ, Vale WW, Rivier CL: Increased pituitary sensitivity to glucocorticoid feedback during the stress nonresponsive period in the neonatal rat. Endocrinology 1986;119:1816-1821. 


\section{Erratum}

In the article by Nascimento AF, Alves GJ, Massoco CO, Teodorov E, Felicio LF and Bernardi MM, entitled 'Lipopolysaccharide-Induced Sickness Behavior in Lactating Rats Decreases Ultrasonic Vocalizations and Exacerbates Immune System Activity in Male Offspring' [Neuroimmunomodulation 2015;22, DOI: 10.1159/000363350], an error occurred in table 1 and in the text.

Please find below the corrected table row and text passage.

\begin{tabular}{lllll}
\hline Parameter & Groups & $\mathrm{p}$ \\
\cline { 2 - 3 } & control & experimental & \\
\hline $\begin{array}{l}\text { Maternal behavior } \\
\text { Latency to retrieve of 3rd pup, s }\end{array}$ & $395.26 \pm 27.27$ & $191.80 \pm 56.10$ & 0.001 \\
\hline
\end{tabular}

Section Discussion, page 6, second column, second paragraph, line 7 from the bottom: Therefore, the decrease in the latency to retrieve the third pup observed in lactating LPStreated rats in the present study may be attributable to a slight improvement in maternal care.

\section{Acknowledgement}

L.F.F. was supported by FAPESP (Grant \#2013/01610-7). 